\section{Personality by intelligence interaction effects on grades tend to be synergistic}

\author{
Kimmo Sorjonen ${ }^{1}$, Alma Sörberg Wallin² ${ }^{2}$, Daniel
} Falkstedt $^{3}$, \& Bo Melin ${ }^{1}$

${ }^{1}$ Department of Clinical Neuroscience, Karolinska Institutet, Stockholm, Sweden

2 Department of Global Public Health, Karolinska Institutet, Stockholm, Sweden

${ }^{3}$ Institute of Environmental Medicine, Karolinska Institutet, Stockholm, Sweden

\section{Abstract}

Earlier research has identified personality traits $x$ intelligence interaction effects on academic performance. The present study, employing data from the 1997 National Longitudinal Survey of Youth (NLSY97, $N=8984$ ), identified some interaction effects, mainly involving indicators of dependability, on high school grades. The interaction effects tended to be synergistic, meaning that the association between the trait and grades tended to strengthen with increased intelligence. This could be due to a sufficient level of intelligence being necessary for higher grades, and that lack thereof cannot be compensated for by a high degree of some advantageous personality trait. However, a positive association between intelligence and reliability in the measurement of personality, as well as a reversed causal effect of grades on self-rated personality moderated by intelligence, could also be contributing causes to the tendency for synergistic interaction effects.

Keywords: academic achievement, intelligence, interaction effect, personality traits, reliability, reversed causality, synergistic

\section{Introduction}

Studies have identified personality traits $\times$ intelligence interaction effects on academic performance. More often than not, these interaction effects seem to be synergistic, i.e. the association between the personality trait and academic performance strengthens with increased intelligence. For example, among students, an increase in intelligence has been found to strengthen the positive association between grades and conscientiousness (Bergold \& Steinmayr, 2018; Di Domenico \& Fournier, 2015; Ziegler et al., 2009). Lozano et al. (2014) observed that impulsivity was more strongly negatively associated with grades among more intelligent compared to less intelligent students. Furthermore, in a study among mainly Hispanic STEM (Science, Technology, Engineering, and Mathematics) students, an increase in intelligence strengthened the negative association between agreeableness and grades (Fagan et al., 2019). Heaven and Ciarrochi (2012) observed a stronger association between openness/intellect and grades among students with higher compared to those with lower intelligence. However, compensatory interaction effects, where the association between the trait and academic outcomes weaken with increased intelligence, have also been reported. For example, an increase in intelligence seems to weaken the positive association between grades and need for cognition (Strobel et al., 2019). In contradiction to the finding by Heaven and Ciarrochi (2012) mentioned above, Zhang and Ziegler (2015) found that the positive association between openness and grades in a sample of students weakened with increased intelligence. An increase in fluid intelligence has also been found to weaken the positive association between openness and crystallized intelligence (Ziegler et al., 2012).

However, observed interaction effects should not always be taken at face value. In his pivotal paper, Ganzach (1997) made the simple, but eloquent, argument that if two predictors, $X_{1}$ and $X_{2}$, are correlated, the $X_{1} \times X_{2}$ interaction term will tend to be correlated with the quadratic terms $\mathrm{X}_{1}{ }^{2}$ and $\mathrm{X}_{2}{ }^{2}$

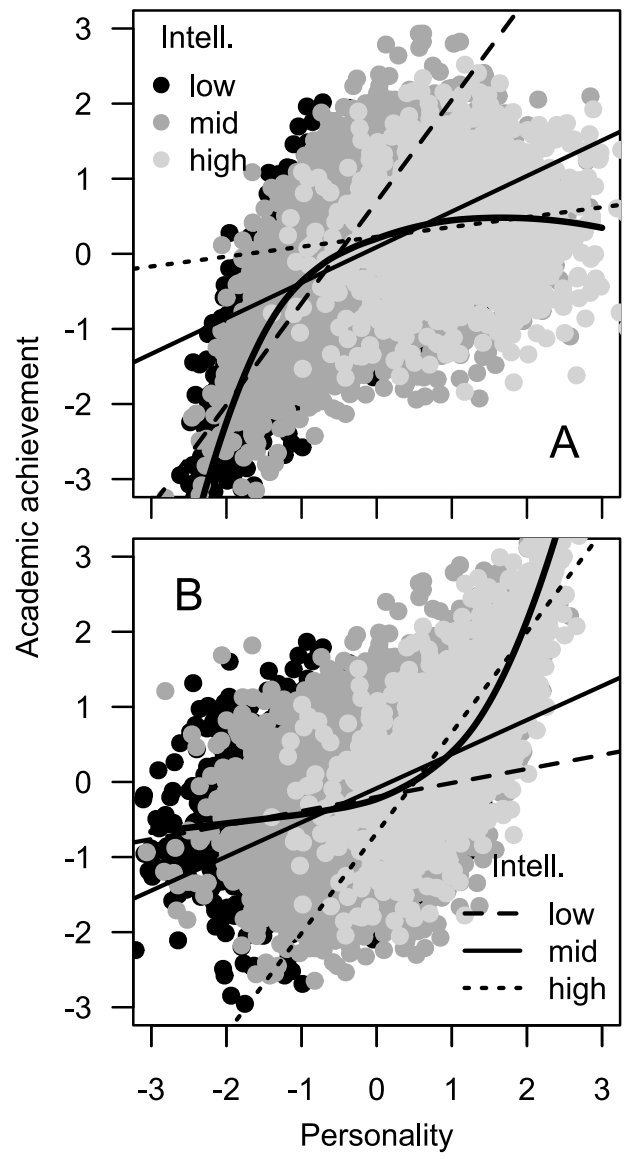

Figure 1. A compensatory (A) and a synergistic (B) intelligence $\times$ personality interaction effect on academic achievement that is due to a concave (A) and a convex (B) association between personality and academic achievement, respectively, in combination with a positive association between intelligence and the personality trait. Simulated data. 
and, consequently, an identified interaction effect on the outcome $\mathrm{Y}$ may be due to a quadratic association between $\mathrm{Y}$ and $\mathrm{X}_{1}$ or $\mathrm{X}_{2}$ or, vice versa, an identified quadratic association between $\mathrm{Y}$ and $\mathrm{X}_{1}$ or $\mathrm{X}_{2}$ may be due to an interaction effect (Figure 1). Therefore, it is advisable to adjust for possible quadratic associations when claiming that $\mathrm{X}_{1}$ and $\mathrm{X}_{2}$ interact in their effect on $\mathrm{Y}$, and, vice versa, to adjust for the interaction if claiming a quadratic association.

The objective of the present study was to: (1) Analyze if there are intelligence $\times$ personality trait interaction effects on academic achievement, operationalized as grade point average and highest degree achieved, in the 1997 National Longitudinal Study of Youth (NLSY97) dataset; (2) Analyze if interaction effects remain significant when adjusting for possibly quadratic associations between personality/intelligence and academic achievement; (3) Evaluate if adjusted interaction effects tend to be synergistic or compensatory.

Method

\section{Respondents}

Data were collected from 8984 US respondents (4385 women and 4599 men), born between 1980 and 1984, who took part in the 1997 National Longitudinal Survey of Youth (NLSY97).

\section{Measurements}

Most respondents (complete data available for 7008 individuals) took 12 Armed Services Vocational Aptitude Battery (ASVAB) tests in 1997-1998: (1) general science; (2) arithmetic reasoning; (3) word knowledge; (4) paragraph comprehension; (5) numerical operations; (6) coding speed; (7) auto information; (8) shop information; (9) mathematical knowledge; (10) mechanical comprehension; (11) electronics information; (12) assembling objects.

On later occasions, the respondents rated to what degree they felt that a number of personality items were descriptive of themselves: (1) disorganized, (2) conscientious, (3) undependable, (4) thorough, (5) agreeable, (6) difficult, (7) stubborn, (8) trustful, (9) extraverted/enthusiastic, (10) critical/ quarrelsome, (11) dependable/ self-disciplined, (12) anxious/ easily upset, (13) open/ complex, (14) reserved/ quiet, (15) sympathetic/ warm, (16) disorganized/ careless, (17) calm/ emotionally stable, (18) conventional/ uncreative. Items 1-8 were rated in 2002 on a scale from 1 to 5 ( $n$ between 4857 and 4875 ) while items 9-18 were rated in 2008 on a scale from 1 to 7 ( $n$ between 7195 and 7457). Three composite scores were created: (a) Dependable, including items 1 (reversed), 3 (reversed), 4, 11, 16 (reversed), and 17, coefficient omega $=0.56$; $(\mathrm{b})$ Agreeable, including items 5, 6 (reversed), 7 (reversed), and 8, coefficient omega $=0.60 ;$ (c) Open, including items 9, 12 (reversed), 13, 14 (reversed), 15, and 18 (reversed), coefficient omega $=0.50$.

Credit weighted overall grade point average (GPA) was available, as transcript survey data from high schools, for 6004 respondents. Moreover, in 2017 respondents were asked about their highest academic degree received, with the values: (0) None, $n=515$, (1) General educational development, $n=862$, (2) High school diploma, $n=$ 2692, (3) Associate/junior college, $n=598$, (4) Bachelor's degree, $n=1352$, (5) Master's degree, $n$ $=540$, (6) Professional degree $/ \mathrm{PhD}, n=149$. Data on degree was available for 6708 respondents.

\section{Statistical analyses}

Factor scores on the first unrotated factor in an analysis of all 12 ASVAB tests was used as an estimate of the respondents' general intelligence. The scores on each personality item as well as the three composites were standardized and the correlation with intelligence and grades/degree as well as the item $\times$ intelligence interaction effect on grades/degree were calculated. The interaction effects were estimated both without and with adjustment for possible quadratic associations. In the latter case the predicted grade/degree is given by:

$$
\begin{gathered}
E|g r / d e|=b_{0}+b_{1} \times \text { intell }+b_{2} \times \text { intell }^{2}+b_{3} \times \text { pers }+ \\
b_{4} \times \text { pers }^{2}+b_{5} \times \text { intell } \times \text { pers }
\end{gathered}
$$

If the personality $\times$ intelligence interaction effect on grades/degree tends to be synergistic or complementary, we should see a positive or a negative association between the itemgrades/degree correlation and the coefficient for the item $\times$ intelligence interaction effect, respectively. The present study included 195 tests of significance, and if wishing to be cautious not to conduct type 1errors, a conservative Bonferroni correction could be used to set the significance level at $0.05 / 195=$ 0.000256 . Analyses were conducted with R 4.1.0 statistical software (R Core Team, 2021) employing the psych package (Revelle, 2020). Code and dataset are available at https://osf.io/2fsca/.

\section{Results}

Intelligence had a positive association both with grade point average $(\beta=0.459, p<0.001)$ and with highest degree achieved $(\beta=0.506, p<0.001)$. A quadratic intelligence term was significant in the model predicting grades $(\beta=0.039, p<0.001)$ but it only contributed to increase $R$-squared from 0.204 to 0.206 . A quadratic intelligence term had no significant association with highest degree $(p=$ 0.922).

Associations involving the 18 personality items and the three composite scores can be seen in Table 1. It can be noted that (a) The personality traits tend to have only weak linear associations with intelligence (column 1), grades (column 2), and 


\begin{tabular}{|c|c|c|c|c|c|c|c|c|c|}
\hline \multirow[b]{2}{*}{ Personality item } & \multirow[b]{2}{*}{ 1.r(iq $)^{\mathrm{a}}$} & \multicolumn{4}{|c|}{ Grade Point Average } & \multicolumn{4}{|c|}{ Highest Degree Achieved } \\
\hline & & $2 . r(\mathrm{gr})^{\mathrm{b}}$ & $3 . b\left(\mathrm{pe}^{2}\right)^{\mathrm{c}}$ & 4.Int- $\mathrm{C}^{\mathrm{d}}$ & 5.Int- $\mathrm{A}^{\mathrm{e}}$ & $6 . r(\mathrm{de})^{\mathrm{b}}$ & $7 . b\left(\mathrm{pe}^{2}\right)^{\mathrm{c}}$ & 8.Int-C ${ }^{\mathrm{d}}$ & 9.Int-A \\
\hline 1.disorganized $^{\mathrm{f}}$ & $0.032 *$ & $-0.074 * *$ & 0.005 & $-0.069^{* *}$ & $-0.072 * *$ & $-0.084^{* *}$ & 0.005 & -0.028 & -0.028 \\
\hline 2.conscientious & $0.188 * *$ & $0.167 * *$ & $0.041 *$ & $0.043^{*}$ & 0.035 & $0.139^{* *}$ & 0.016 & $0.04 *$ & $0.043^{*}$ \\
\hline 3.undependable ${ }^{f}$ & $-0.128 * *$ & $-0.125^{* *}$ & 0.027 & $-0.068^{*}$ & $-0.062 *$ & $-0.159 * *$ & 0.018 & -0.009 & -0.005 \\
\hline 4.thorough ${ }^{f}$ & $0.080 * *$ & $0.090 * *$ & -0.021 & $0.037^{*}$ & 0.033 & $0.102 * *$ & $-0.038 *$ & 0.002 & 0.002 \\
\hline 5.agreeable ${ }^{g}$ & 0.028 & $0.088 * *$ & -0.022 & 0.026 & 0.024 & $0.097 * *$ & -0.023 & 0.021 & 0.023 \\
\hline 6.difficult ${ }^{\mathrm{g}}$ & $-0.085 * *$ & $-0.114 * *$ & $-0.048 *$ & -0.025 & -0.024 & $-0.134 * *$ & $-0.052 * *$ & -0.004 & -0.004 \\
\hline 7.stubborn ${ }^{\mathrm{g}}$ & $0.080 * *$ & -0.001 & $-0.065^{* *}$ & 0.008 & 0.003 & -0.031 & $-0.080 * *$ & -0.018 & -0.016 \\
\hline 8.trustfulg & $0.059 * *$ & $0.057 *$ & -0.012 & 0.032 & 0.032 & $0.067 * *$ & -0.007 & -0.001 & -0.001 \\
\hline 9. extraverted ${ }^{\mathrm{h}}$ & 0.009 & $0.043 *$ & 0.000 & -0.005 & -0.003 & $0.072 * *$ & -0.009 & -0.017 & -0.018 \\
\hline 10.critical & $-0.043 *$ & $-0.054 * *$ & -0.007 & $-0.052 * *$ & $-0.052 * *$ & $-0.057 * *$ & $-0.030 *$ & $-0.027 *$ & $-0.028 *$ \\
\hline 11.dependable $\mathrm{f}^{\mathrm{f}}$ & -0.001 & $0.072 * *$ & $-0.021 *$ & $0.041 *$ & $0.039 *$ & $0.076^{* *}$ & $-0.045 * *$ & $0.036^{*}$ & $0.042 *$ \\
\hline 12. anxious $^{\mathrm{h}}$ & $-0.199 * *$ & $-0.109 * *$ & $-0.070 * *$ & -0.005 & 0.001 & $-0.169^{* *}$ & $-0.100 * *$ & 0.021 & 0.010 \\
\hline 13.open ${ }^{\mathrm{h}}$ & 0.018 & -0.003 & $-0.052 * *$ & -0.003 & 0.002 & $0.056^{* *}$ & $-0.069 * *$ & 0.004 & 0.010 \\
\hline 14.reserved ${ }^{\mathrm{h}}$ & $-0.122 * *$ & $-0.062 * *$ & $-0.053^{*}$ & -0.021 & -0.019 & $-0.085^{* *}$ & $-0.098 * *$ & 0.016 & 0.011 \\
\hline 15.sympathetic ${ }^{\mathrm{h}}$ & $0.050 * *$ & $0.069 * *$ & -0.016 & $0.039 *$ & $0.037 *$ & $0.093^{* *}$ & $-0.049 * *$ & 0.014 & 0.016 \\
\hline 16.careless $\mathrm{f}^{\mathrm{f}}$ & $0.044 *$ & $-0.065 * *$ & $-0.048 *$ & $-0.048^{*}$ & $-0.051 * *$ & $-0.067 * *$ & $-0.082 * *$ & $-0.028^{*}$ & $-0.029 *$ \\
\hline 17.calm $\mathrm{f}$ & $0.033^{*}$ & $0.045^{*}$ & $-0.029 *$ & 0.014 & 0.012 & $0.087^{* * *}$ & $-0.050 * *$ & 0.015 & 0.017 \\
\hline 18.conventional ${ }^{\mathrm{h}}$ & $-0.077 * *$ & -0.007 & $-0.060 * *$ & -0.001 & 0.003 & $-0.034^{*}$ & $-0.07 * *$ & 0.012 & 0.012 \\
\hline \multicolumn{10}{|l|}{ Composite } \\
\hline 19.dependable & 0.022 & $0.114 * *$ & $-0.018 *$ & $0.059^{* *}$ & $0.057 * *$ & $0.139 * *$ & $-0.029 * *$ & $0.031^{*}$ & $0.032 *$ \\
\hline 20.agreeable & $0.035^{*}$ & $0.096 * *$ & $-0.037 *$ & 0.026 & 0.025 & $0.124 * *$ & -0.021 & 0.012 & 0.012 \\
\hline 21.open & $0.152 * *$ & $0.092 * *$ & -0.017 & 0.016 & 0.010 & $0.162 * *$ & $-0.018 *$ & $-0.023^{*}$ & $-0.026 *$ \\
\hline \multicolumn{10}{|c|}{$\begin{array}{l}\text { a correlation with intelligence, }{ }^{\mathrm{b}} \text { correlation with grades/degree, }{ }^{\mathrm{c}} \text { quadratic term for the association with grades/degree, }{ }^{\mathrm{d}} \text { crude intelligence } \times \\
\text { personality interaction effect on grades/degree, not adjusting for quadratic terms, }{ }^{\mathrm{e}} \text { intelligence } \times \text { personality interaction effect on grades/degree, } \\
\text { adjusted for quadratic terms, }{ }^{\mathrm{f}} \text { included in the Dependable composite, }{ }^{\mathrm{g}} \text { included in the Agreeable composite, }{ }^{\mathrm{h}} \text { included in the Open composite, } * p< \\
0.05, * * p<0.000256\end{array}$} \\
\hline
\end{tabular}

degree (column 6), with conscientious (row 2) and the open composite score (row 21) having the strongest positive associations and undependable (row 3) and anxious (row 12) the strongest negative associations; (b) Only conscientious has a significant positive quadratic association with grades (but not with degree) while several other personality items - including stubborn, anxious, and reserved - have a negative quadratic associations both with grades and with degree. This suggests that with a further increase beyond a certain level, the negative association between these traits and grades/degree strengthen with increasing speed; (c) The personality $\times$ intelligence interaction effects do not change much when adjusting for quadratic terms (compare columns 4 and 5, and 8 and 9, respectively); (d) Among the interaction effects we can note that the negative associations between grades and disorganized, critical, and careless strengthen with increasing intelligence as does the positive association between grades and the dependable composite score.

A closer look at the intelligence $\times$ dependable composite score interaction effect on grades indicates that the weaker (actually non-existent) association among those with low intelligence $(\leq-1$ standardized score) may, at least to some degree, be due to some individuals rating themselves high on the personality trait but still receiving very low grades (Figure 2, panel A). This combination of high self-rated dependability and low grades is not seen to the same degree among those with high $(Z \geq 1)$ intelligence (Figure 2, panel B). It can, furthermore, be noted that the reliability in the measurement of the dependable composite score was lower among those with low compared to those with high intelligence, with coefficient omega equal to 0.51

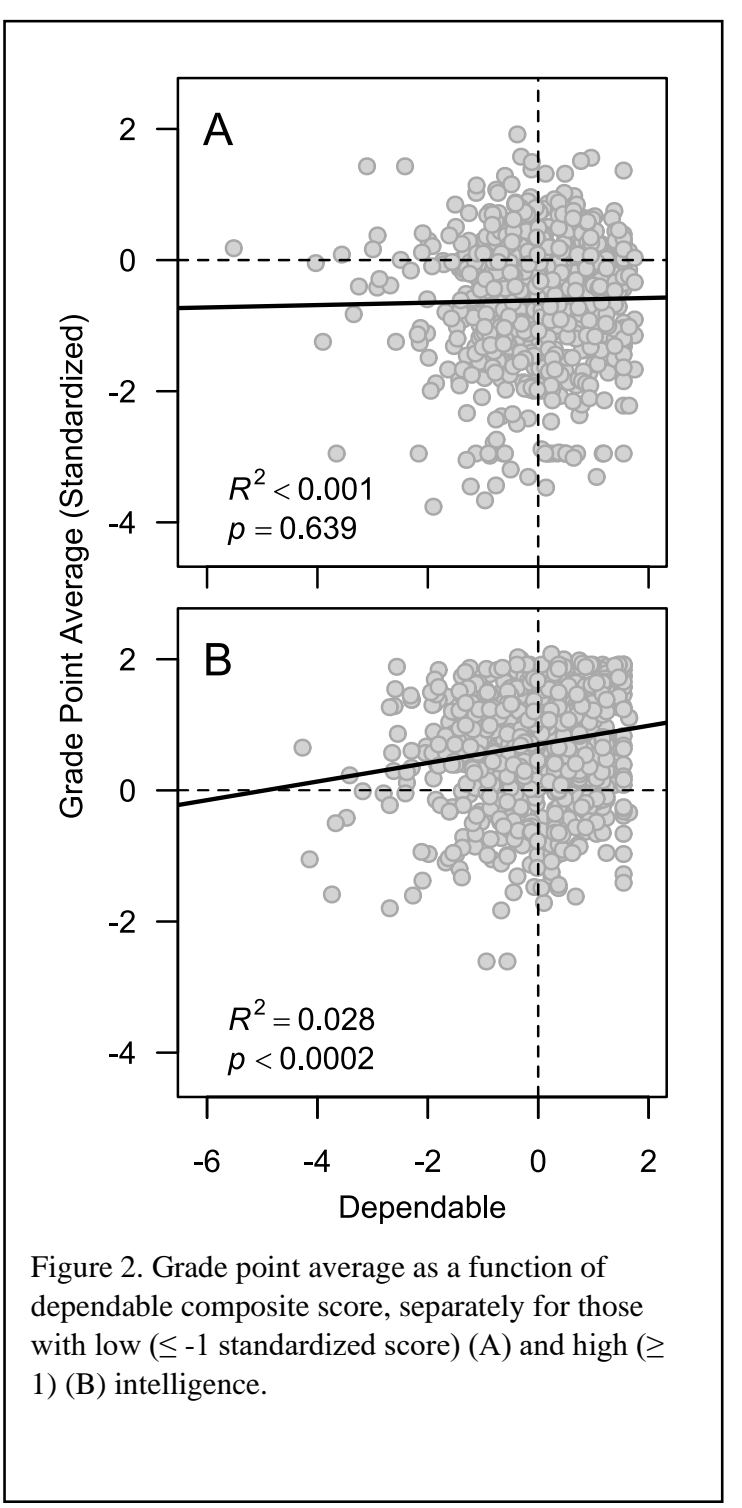


and 0.65 , respectively. A similar difference in reliability was seen on the agreeable (omega $=0.54$ and 0.66 , respectively) and open (omega $=0.36$ and 0.58 , respectively) composite scores.

A positive association between the correlation between the personality items/composites and academic achievement (columns 2 and 6 in Table 1 for grades and for degree, respectively) and the personality $\times$ intelligence interaction term (columns 5 and 9 in Table 1) indicates that the interaction effects tend to be synergistic, at least on grades (Figure 3). This means that the association between personality traits and grades, positive or negative, tend to strengthen with an increase in intelligence.

Lastly, it can be noted that the personality traits contribute quite little to the prediction of academic achievement over and above the contribution of intelligence. The linear association with intelligence can account for $20.4 \%$ and $26.3 \%$ of the variance in grades and in degree, respectively, and these values increase to maximally $25.5 \%$ (with the disorganized

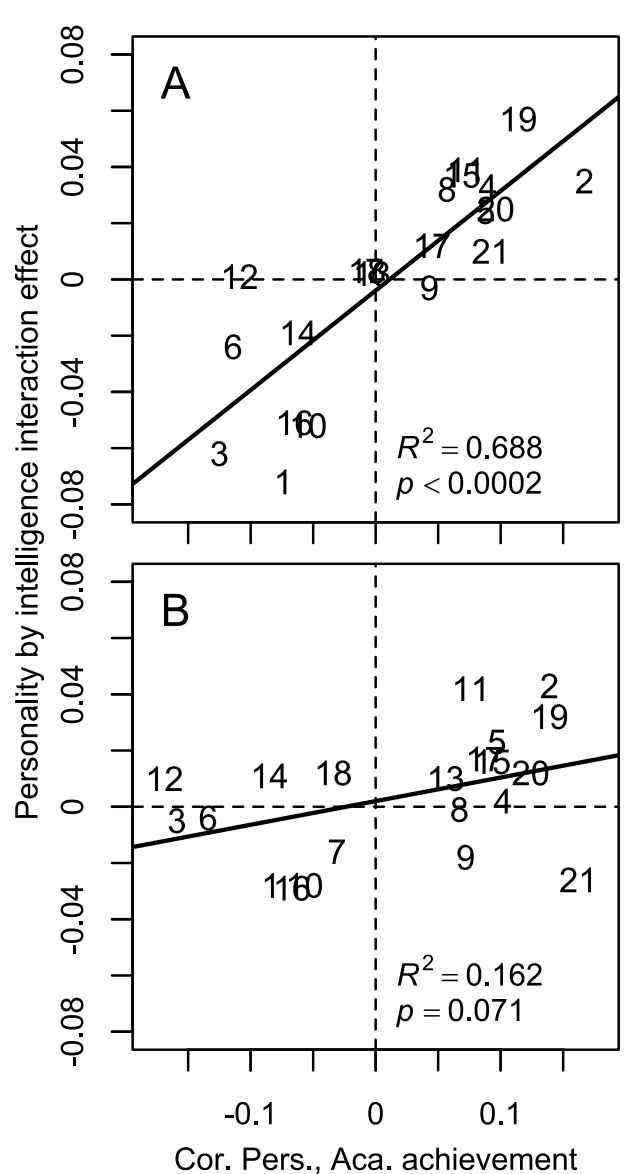

Figure 3. The personality trait $\times$ intelligence interaction effect on grade point average (A) and highest degree achieved (B) as a function of the correlation between the personality trait and grades/degree. The numbers correspond to rows in Table 1, where the interaction effects can be found in columns 5 and 9 and the correlations in columns 2 and 6 , respectively. item) and $28.0 \%$ (with the dependable composite score) in full models including quadratic terms as well as a personality $x$ intelligence interaction term (as in Eq. 1).

\section{Discussion}

The present findings suggest that some indicators of personality traits, mainly related to dependability, interact with intelligence in their association with academic achievements, mainly high school grades. Furthermore, personality trait $x$ intelligence interaction effects tended to be synergistic, which means that the association between the trait and grades, positive or negative, tended to strengthen with increased intelligence. One possible reason for this is that intelligence may be some kind of necessary condition for academic achievement, and if intelligence is too low it cannot be compensated for by a high degree of some advantageous trait like dependability. On the other hand, if intelligence is low, a high degree of some disadvantageous trait like being very critical or careless may not decrease academic achievement much further, i.e. there may be some kind of floor effect involved. For those with sufficiently high intelligence, on the other hand, personality traits may contribute to pushing grades a little bit up- or downward, although the influence of personality seems quite limited compared with intelligence.

Observed associations tend to weaken with a decrease in the reliability of measurements. Consequently, a positive association between intelligence and the reliability in the measurement of personality, as observed in the present study, could be another contributing cause to the tendency for synergistic personality $x$ intelligence interaction effects on grades. Earlier studies have found, for example, positive associations between respondents' intelligence and response consistency on measures of the Big Five personality traits (Allik et al., 2004; Austin et al., 1997; Escorial et al., 2019), but also on measures of psychological maturity, impulsivity, aggression, and callousness (NavarroGonzález et al., 2018), measures of youth delinquency (Pinsoneault, 1998), and attitudes toward a strong military defense (Sorjonen et al., 2020). It has been proposed that this association between intelligence and reliability in measurements may be due to, for example, lack of motivation/ carelessness, worse working memory, inadequate reading ability, and poorer understanding of questionnaire items among some respondents, which would tend to result in low performance on intelligence tests as well as low reliability in measurements of attitudes and personality (Austin et al., 1997; Sorjonen et al., 2020). It has also been suggested that people with high intelligence actually tend to have more distinctive personalities compared to those with lower intelligence (Brand et al., 1994). 
In the present study, personality traits $\times$ intelligence interaction effects were mainly seen on grades and to a lesser degree on highest degree achieved. One reason for this difference could be the slightly stronger association between intelligence and degree $(\beta=0.506)$ compared to the association between intelligence and grades $(\beta=0.459)$. This could result in less elbow room for personality to have an influence on degree than on grades when including intelligence as a predictor in the model.

The measurement of personality is the most obvious limitation in the present study. We used mostly single item measures and the three composite scores had mediocre reliability/consistency. However, low reliability in measurements should tend to decrease power rather than increase risk for type 1-errors. With more reliable full-scale measures of personality traits, we should, consequently, probably have seen more significant synergistic personality $\times$ intelligence interaction effects rather than elimination of the presently observed interactions or, even less likely, a reversal from synergistic to compensatory interaction effects.

Another limitation is that the personality items were measured in 2002 and 2008, when the respondents were between 18 and 22 and between 24 and 28 years old, respectively, i.e. in many cases after they had received their high school grades and achieved their highest academic degree. Therefore, any strong conclusions about causality are excluded and there is a possibility that academic achievement may have influenced the respondents' self-view and, consequently, how they rated themselves on the personality items. Moreover, it is possible that such a reversed causal effect of academic achievement on self-rated personality may tend to be stronger among individuals with high compared to those with low intelligence. The self-view of individuals with low intelligence may, as a manner of speaking, be more immune to actual outcomes. This could possibly explain, at least to some degree, the synergistic personality $x$ intelligence interaction effects on academic achievement observed in the present and some other studies. If intelligence moderates a possible effect of outcomes, academic or otherwise, on self-view could actually be an interesting subject for future research, with the added benefit that outcomes, differently from self-rated personality, can be experimentally manipulated.

\section{Conclusions}

Personality trait $\times$ intelligence interaction effects on grades tend to be synergistic, i.e. the association between the trait and grades, if it exists, tends to strengthen with increased intelligence. This could, for example, be due to a sufficient level of intelligence being necessary for higher grades, and that lack thereof cannot be compensated for by a high degree of some advantageous personality trait. A positive association between intelligence and reliability in the measurement of personality, as well as a reversed causal effect of grades on self-rated personality moderated by intelligence, could also be contributing causes to the tendency for synergistic interaction effects.

Data availability

Data and script for the present study is available at Open Science Framework at https://osf.io/2fsca/

\section{References}

Allik, J., Laidra, K., Realo, A., \& Pullmann, H. (2004). Personality development from 12 to 18 years of age: Changes in mean levels and structure of traits. European Journal of Personality, 18(6), 445-462. https://doi.org/10.1002/per.524

Austin, E. J., Deary, I. J., \& Gibson, G. J. (1997). Relationships between ability and personality: Three hypotheses tested. Intelligence, 25(1), 49-70. https://doi.org/10.1016/S0160-2896(97)90007-6

Bergold, S., \& Steinmayr, R. (2018). Personality and intelligence interact in the prediction of academic achievement. Journal of Intelligence, 6(2), 27. https://doi.org/10.3390/jintelligence6020027

Brand, C., Egan, V., \& Deary, I. (1994). Intelligence, personality, and society: "Constructivist" versus "essentialist" possibilities. In D. K. Detterman (Ed.), Theories of intelligence (pp. 29-42). Ablex Publ. Corp.

Di Domenico, S. I., \& Fournier, M. A. (2015). Able, ready, and willing: Examining the additive and interactive effects of intelligence, conscientiousness, and autonomous motivation on undergraduate academic performance. Learning and Individual Differences, 40, 156-162. https://doi.org/10.1016/j.lindif.2015.03.016

Escorial, S., Navarro-González, D., Ferrando, P. J., \& Vigil-Colet, A. (2019). Is individual reliability responsible for the differences in personality differentiation across ability levels? Personality and Individual Differences, 139, 331-336. https://doi.org/10.1016/j.paid.2018.12.004

Fagan, M. A., Hull, D. M., Gray, R., \& Bolen, J. A. (2019). Predicting STEM performance in a Hispanic serving institution. Personality and Individual Differences, 141, 18-24. https://doi.org/10.1016/j.paid.2018.12.017

Ganzach, Y. (1997). Misleading interaction and curvilinear terms. Psychological Methods, 2(3), 235247.

Heaven, P. C. L., \& Ciarrochi, J. (2012). When IQ is not everything: Intelligence, personality and academic performance at school. Personality and Individual Differences, 53(4), 518-522. https://doi.org/10.1016/j.paid.2012.04.024

Lozano, J. H., Gordillo, F., \& Pérez, M. A. (2014). Impulsivity, intelligence, and academic performance: Testing the interaction hypothesis. Personality and Individual Differences, 61-62, 63-68. https://doi.org/10.1016/j.paid.2014.01.013

Navarro-González, D., Ferrando, P. J., \& Vigil-Colet, A. (2018). Is general intelligence responsible for differences in individual reliability in personality measures? Personality and Individual Differences, 130, 1-5. https://doi.org/10.1016/j.paid.2018.03.034 
Pinsoneault, T. B. (1998). A Variable Response Inconsistency Scale and a True Response Inconsistency Scale for the Jesness Inventory. Psychological Assessment, 10(1), 21-32. https://doi.org/10.1037/1040-3590.10.1.21

$\mathrm{R}$ Core Team. (2021). $R$ : A language and environment for statistical computing. $R$ Foundation for Statistical Computing, Vienna, Austria. URL https://www.Rproject.org/.

Revelle, W. (2020). psych: Procedures for personality and psychological research, Northwestern University, Evanston, Illinois, USA, https://CRAN.Rproject.org/package $=$ psych Version $=2.0 .7$.

Sorjonen, K., Hemmingsson, T., \& Melin, B. (2020). Intelligence, consistency, and Emerson's dilemma. Personality and Individual Differences, 160, 109943. https://doi.org/10.1016/j.paid.2020.109943

Strobel, A., Behnke, A., Gärtner, A., \& Strobel, A. (2019). The interplay of intelligence and need for cognition in predicting school grades: A retrospective study. Personality and Individual Differences, 144, 147-152. https://doi.org/10.1016/j.paid.2019.02.041
Zhang, J., \& Ziegler, M. (2015). Interaction Effects between Openness and Fluid Intelligence Predicting Scholastic Performance. Journal of Intelligence, 3(3), 91-110. https://doi.org/10.3390/jintelligence3030091

Ziegler, M., Danay, E., Heene, M., Asendorpf, J., \& Bühner, M. (2012). Openness, fluid intelligence, and crystallized intelligence: Toward an integrative model. Journal of Research in Personality, 46(2), 173-183. https://doi.org/10.1016/j.jrp.2012.01.002

Ziegler, M., Knogler, M., \& Bühner, M. (2009). Conscientiousness, achievement striving, and intelligence as performance predictors in a sample of German psychology students: Always a linear relationship? Learning and Individual Differences, 19(2), 288-292.

https://doi.org/10.1016/j.lindif.2009.02.001 